\title{
MODALIDADES Y NIVELES DE INTERACTIVIDAD EN LA TELEVISIÓN DIGITAL TERRESTRE
}

\author{
Mariano Cebrián Herreros \\ (Universidad Complutense de Madrid) \\ marceb@ccinf.ucm.es
}

\begin{abstract}
Resumen: La interactividad se ha hecho tan compleja que ya no debe utilizarse como un concepto unitario, sino que es necesario ampliar su dimensión a las modalidades y niveles que en cada caso concreto se empleen. La originalidad del objetivo de este artículo es la de indagar en la identificación y sistematización de estos modelos desde los dirigistas hasta los más creativos dentro de los servicios interactivos existentes en la TDT en España. La aportación se enmarca en las investigaciones básicas al proponer una conceptualización y una tipología del fenómeno analizado que sirvan de fundamento para posteriores investigaciones aplicadas.
\end{abstract}

Palabras clave: Televisión, digital, TDT, interactividad, servicios interactivos.

Abstract: The interactivity has become so complex that no longer be used as a unitary concept but it is necessary to extend her dimension to the modalities and levels that in every case are used. The objective of this article is of investigating the identification and systematizing of these models from the directives to the most creatives within the existing interactive services on DTT in Spain. The contribution is part of basic research in proposing a conceptualization and a typology of the phenomenon analysed to serve as foundation for subsequent applied research.

Keywords: Television, digital, DTT, interactivity, interactive services.

\section{INTRODUCCIÓN}

na de las obsesiones de la televisión digital terrestre (TDT) desde sus inicios ha sido la de incorporar la interactividad. Fue la última en aparecer, tras el satélite y el cable, y cuando llegaron los contenidos de mayor atractivo para los telespectadores ya estaban contratados en exclusiva por las anteriores. Ante esta situación la TDT apostó por ofrecer algo original: los servicios interactivos vinculados a la programación o a los programas y los canales exclusivamente de servicios de compra-venta, de informaciones sobre el tiempo y otros $^{1}$. La obsesión ha alcanzado a los diseñadores de programas y a los creadores de contenidos y de servicios para introducir la interactividad en todos los procesos.

\footnotetext{
${ }^{1}$ Véase a este respecto los capítulos 6 y 7 dedicados a estos servicios dentro del conjunto de sistemas televisivos en Cebrián (2004).
} 


\section{Modalidades y niveles de interactividad en la Televisión Digital Terrestre}

Pero, además de reconocer su existencia, lo importante es apreciar qué modalidad y con qué nivel se plantea. Aparecen dos enfoques claros: el del sector público y el del sector privado. No es que haya unos exclusivos de un sector o de otro. Son diferencias de enfoques y a veces de propuestas. De ahí que se debatan entre el enfoque para la comunicación e información de servicio público y el enfoque de negocio. Los servicios de comunicación social y cultural (sin afán de lucro) deberían aparecer prioritariamente en el sector público, mientras que los servicios para el negocio (con afán de lucro), prioritariamente en el sector privado. No obstante, los dos enfoques aparecen en ambos sectores, aunque se echa en falta la apuesta clara por los servicios sociales, culturales y educativos en el sector público.

El término interactividad se ha constituido en un comodín del marketing usado y abusado para describir cualquier situación aunque sólo sea, como sucede a veces, para definir la operación del mando a distancia que permite pasar de un canal a otro o para referirse a accesos en los que el usuario apenas ejerce actividad alguna, salvo la de presionar un número para elegir una opción determinada. Pero ¿cuál es el campo real de la interactividad?, ¿cuáles son los servicios auténticos de interactividad?, ¿existen niveles con menor o mayor interactividad? Son preguntas a las que debe dar respuesta una investigación rigurosa ya que se ha convertido en un nuevo campo y objeto específicos.

Lo primero que hay que poner de relieve es la necesidad de saltar de los servicios interactivos tecnológicos a los comunicativos. Lo tecnológico constituye la infraestructura sin la cual nada puede hacerse, pero es sólo una base para lo comunicativo; se establece una vinculación estrecha entre ambos procesos, aunque desde el punto de vista del análisis de contenidos y de servicios haya que centrarse fundamentalmente en la dimensión comunicativa. Los servicios interactivos comunicativos van más allá de lo tecnológico y jurídico al estar envueltos en un entorno económico, político, social y cultural y según las connotaciones de cada uno de los usuarios en particular o de la comunidad ${ }^{2}$. Su valoración hay que establecerla por la exigencia de su eficacia comunicativa y de negocio y, además, por la exigencia de creatividad comunicativa que deben mostrar.

Para determinar el alcance de la comunicación interactiva hay que diferenciar entre lo que es la interacción (acción recíproca entre dos personas, animales u objetos), y la interactividad o diálogo mediante un programa informático entre usuarios y ordenador ${ }^{3}$. La interactividad incorpora en igualdad comunicativa a los usuarios emisores y receptores. Esto requiere un cambio de mentalidad de difusión a otra de diálogo y de fomento de la creatividad en los usuarios.

\footnotetext{
${ }^{2}$ Es una línea desarrollada por el grupo GAPTEL (2005) que trata de examinar las interrelaciones de todos estos componentes con una visión de conjunto de todo el proceso que genera la TDT.

${ }^{3}$ El Diccionario de la Real Academia diferencia claramente ambos: Interactivo, va. Adj. Que procede por interacción. II 2.Inform. Dícese de los programas que permiten una interacción, a modo de diálogo, entre el computador y el usuario. Ú.t.c.s.m. Interacción. F. Acción que se ejerce recíprocamente entre dos o más objetos, agentes, fuerzas, funciones, etc.
} 
La interactividad transforma los modelos clásicos de comunicación deducidos de los medios unidireccionales. Se pasa de los modelos lineales a la construcción de los interactivos. Los dos componentes relacionados, emisores y receptores, se sitúan en igualdad, horizontalidad e intercambio de los papeles. Para cuantificar y cualificar la comunicación interactiva hay que centrarse en la función que se otorga al tradicional receptor. Además hay que establecer una vinculación de la interactividad con las búsquedas y enlaces.

La interactividad ha conseguido su mayor desarrollo en Internet y en los sistemas multimedia de soportes de grabación-reproducción (Cebrián, 2005: 81-102), pero también los demás sistemas de difusión tradicional por satélite, cable y ondas hertzianas buscan el desarrollo de la interactividad por el mismo canal como en el caso del cable o la televisión digital terrestre y el satélite. La televisión digital terrestre experimenta la interactividad mediante el envío de la información por señales hertzianas hasta un soporte registrador, en este caso con los codificadores-descodificadores más o menos complejos, para que el usuario interactúe con la información registrada, pero para mantener una interactividad directa con el canal emisor tiene que utilizar el sistema de cable.

El enfoque de la investigación, cuyos resultados se recogen y sintetizan en este artículo, pone el acento en las modalidades y niveles de interactividad y no, como se viene haciendo en los demás estudios, en torno a la descripción de cada servicio interactivo. Aquí interesa la originalidad de los modelos con objeto de apreciar su aportación a la construcción de los modelos de los procesos de comunicación interactiva.

Existen diversas aportaciones tanto técnicas (Especial Teledigital, 2007) como comunicológicas (Bustamante, 2008; Marzal, y Casero, 2007; AA.VV., 2008), en unos casos con enfoque económico, jurídico (Rodríguez, 2007: 75-137), cultural y, en otros, especialmente en las revistas técnicas y en los congresos y reuniones profesionales, descriptivo de manera muy prolija en cuanto a su funcionamiento técnico y su capacidad de negocio. Pero falta una indagación sobre los diversos modelos comunicativos interactivos y su sistematización en niveles claramente diferenciados que permitan valorar las graduaciones comunicativas interactivas existentes. Ya no debe seguir hablándose de interactividad en general, sino que es preciso investigar en las diferentes modalidades de interactividad existentes para apreciar el diálogo real y, sobre todo, la participación productiva de los usuarios. Se quiere saber hasta dónde llega el talante dialogante de los canales televisivos. Existen ofertas que lo emplean como marketing o prestigio, pero al final se aprecia que es una mera representación ya que el usuario no puede pasar más allá de la selección entre varias opciones. Por el contrario, existen otras que amplían las opciones hasta dar plena creatividad al usuario para que intervenga con sus propias contribuciones al debate o con sus producciones audiovisuales. 


\section{METODOLOGÍA}

Se ha empleado la técnica de análisis de los servicios presentes en los canales digitales terrestres existentes en España ${ }^{4}$ tanto en los de redifusión de los analógicos tradicionales como en los nacidos directamente para la TDT $^{5}$. En lugar de plantear una cuantificación de las veces que se reproduce el fenómeno, ya que se halla en fase de experimentación, de cambio y de sustituciones, ha interesado apreciar las variantes de ofertas, sus innovaciones y modalidades para conseguir establecer una sistematización de las mismas según niveles de complejidad y que van desde el mero planteamiento dirigista de los conductistas hasta los de máximo diálogo e intervención de los constructivistas. De este modo, se ha pretendido que en lugar de seguir utilizando la concepción de la interactividad de manera genérica haya una propuesta rigurosa de los niveles existentes, que es lo que realmente resalta las diferencias de los modelos empleados.

El punto de vista adoptado no es tanto desde la perspectiva de las ofertas de las emisoras cuanto desde las posibilidades de acceso de los usuarios y lo que pueden efectuar con ellos.

Para una mayor exhaustividad de la observación se ha utilizado el equipo MHP por ser el que supera los descodificadores simples y los Set Top Box tradicionales. Hay múltiples servicios que no pueden captarse con el descodificador sencillo y, por tanto, si el análisis se efectúa con él, aunque sea el más común entre los telespectadores que lo tienen instalado en su receptor de la TDT, no podrán apreciarse los servicios en su totalidad ni en su complejidad. Para obtener el mejor resultado es imprescindible trabajar con el sistema que aporte todos los servicios existentes.

Para una mayor elaboración y sistematización se examinan en primer lugar las modalidades de interactividad según diversos parámetros y posteriormente los niveles de interactividad desde los más simples hasta los más complejos. La consideración conjunta de ambas dimensiones permite resaltar el grado de originalidad que presenta el modelo de interactividad empleado en cada una de las situaciones particulares. De este modo, se establece una aportación a la investigación básica para posteriores desarrollos de investigaciones aplicadas.

\footnotetext{
${ }^{4}$ No se entra en la situación de otros países. Aunque algunos de los canales digitales europeos pueden captarse en España mediante los satélites, se crean diversas dificultades para la descodificación de los servicios interactivos que se plantean en esta investigación.

${ }^{5}$ Se han examinado los de cobertura estatal: los cinco de Televisión Española: TVE 1, La 2, 24 Horas, Teledeporte y Clan 50 TVE; los tres de Antena 3: Antena 3, Antena Neox, Antena Nova; los tres de Telecinco: Telecinco, T5 Estrellas, T5 Sport; los tres de Cuatro: Cuatro, CNN +, 40 Latinos; los dos de la Sexta: La Sexta y La Sexta 2; los dos de Veo TV: Veo TV y Veo 2; los dos de Net TV: Net TV y Flymusic; y algunos autonómicos como TV3, y los dos de Telemadrid: Telemadrid y La Otra.
} 


\section{RESULTADOS}

No existe un modelo único de interactividad sino múltiples y según diversos niveles. Además de los modelos concebidos en abstracto, hay que considerar cómo se desarrollan en cada uno de los procesos comunicativos para cualificarlos. De ahí la relevancia de los análisis transversales de los servicios presentes en todos los canales y de los verticales o desarrollo particular en cada uno de ellos, en las diversas ofertas de una plataforma de televisión o en un grupo multimedia de comunicación para establecer una interactividad entre todos los medios propios ${ }^{6}$.

\subsection{Modalidades de interactividad}

Es tal la complejidad de la comunicación interactiva en la televisión digital terrestre que tras los análisis ha habido que establecer diversas perspectivas para apreciar las diferencias de unas y otras modalidades y que esquemáticamente se concretan en torno a los siguientes parámetros ${ }^{7}$.

\subsubsection{Según el uso de la red}

Se centra en la difusión de la programación y redifusión por otras plataformas, pero sin incorporación alguna de interactividad; son emisiones lineales. No obstante, es frecuente que se introduzca la inteligencia de red para beneficiarse de determinados servicios como los de llamadas por telefonía fija o móvil, votaciones y otras actuaciones de los usuarios por una red diferente a la de la emisión como ocurre en la inmensa mayoría de los programas de la televisión generalista analógica y digital terrestre con objeto de atesorar ingresos económicos diferentes a los de la publicidad. Dentro de esta modalidad aparecen unos servicios denominados "casi interactivos" como los de la difusión diferida por varios canales con diversos tiempos de separación: 15, 30 o más minutos para que el usuario cuando llegue a casa pueda elegir desde el principio. Hay también servicios plenamente interactivos que en unos casos pueden estar asociados a la televisión o a otras redes como las telefónicas y en otros ser interactivos in situ, según la capacidad de almacenamiento de los televisores, o a distancia mediante un canal de retorno por la misma u otra red.

\footnotetext{
${ }^{6}$ El recorrido de los servicios interactivos ha sido largo. Desde los primeros momentos en que se inicia en España la TDT con Quiero TV se apuesta por ellos. Pero tras el fracaso de este planteamiento, las experiencias han pasado a las miniplataformas de tres o más canales con los que actúan las empresas concesionarias de estos canales y servicios. Para apreciar su evolución véase la aportación de Emili Prado y David Fernández: "Servicios de televisión interactiva en España. Una historia de claroscuros", en Marzal y Casero (2007: 155-167).

${ }^{7}$ No obstante, no debe incurrirse en la celebración entusiasta de estas modalidades y de los servicios que prestan ya que la inmensa mayoría de ellos están en la fase de experimentación y sólo algunos han conseguido cierta consolidación (AA.VV., 2007).
} 


\section{Modalidades y niveles de interactividad en la Televisión Digital Terrestre}

\subsubsection{Según el tiempo de uso real de cada usuario}

En este caso se diferencia entre los usos en sincronía, es decir, en el mismo momento de la emisión mediante una visualización de los contenidos y de los servicios por la emisora y por el usuario. O bien en asincronía mediante una grabación en un soporte para usos en tiempos diferidos o mediante contenidos conservados en el televisor para que el usuario entre cuando quiera en ellos como en los de la Guía Electrónica de Programación (GEP), el teletexto avanzado y gran parte de los ofrecidos por la emisora. De todo ello se derivan unos usos asimétricos: cada usuario interactúa cuando quiere, pero no desde donde desee salvo que haya un televisor en el lugar elegido.

\subsubsection{Según la vinculación con la programación}

Existen los denominados servicios de lanzadera referidos al acceso a canales de televisión, emisoras de radio y canales de servicios o menú general de uno o varios canales ${ }^{8}$. Adquieren especial relieve los servicios de la GEP, que es una información sobre la programación de todos los canales organizada sobre la oferta del día o sobre días futuros con diversos modos de acceso: programa a programa, recorrido por la programación, fichas completas de programas. Junto a estas ofertas aparecen otros canales dedicados exclusivamente a servicios como los de las entidades bancarias, los de teletienda, tiempo, circulación ${ }^{9}$.

\subsubsection{Según la vinculación con los programas}

En esta variante sobresalen los servicios convergentes en las pantallas como sucede con el paradigmático Canal Bloomberg en el que se aportan simultáneamente diversas ventanas de información escrita fija o en movilidad, además del recuadro propio de un canal convencional de televisión; es un modelo que ha inspirado otros canales. Emergen, asimismo, otros servicios según la concepción de la hipertelevisión, es decir, servicios paralelos y asociados sobre aspectos relacionados con los programas: horarios, géneros, resúmenes, biografías, filmografías, fichas técnicas, proceso de grabación, incluso los chats simultáneos a los programas o los foros abiertos desde la emisión de un programa hasta el siguiente.

\subsubsection{Según la vinculación con los canales}

Se promueve una concepción de multiservicios de las pantallas consistente en la oferta de varios canales para que puedan seguirse simultáneamente como

\footnotetext{
${ }^{8}$ La lanzadera permite identificar a los proveedores de los servicios y visualizar en una sola pantalla la información para dar acceso a todos los contenidos y servicios interactivos ofrecidos por la empresa impulsora del canal o de la miniplataforma de canales.

${ }^{9}$ La propia tecnología digital en su conjunto puede producir, a su vez, grandes transformaciones en la programación tradicional de la televisión. Sin embargo, apenas se ensayan innovaciones y se está incurriendo en un uso meramente instrumental como redifusión de los canales analógicos o con ofertas que siguen los mismos planteamientos de la televisión tradicional. La televisión digital terrestre reclama nuevos modelos de programación (Peñafiel, 2007: 177-187).
} 
ocurre con frecuencia en períodos electorales en los cuales el canal de una plataforma presenta en la misma pantalla, de manera dividida, cuatro o más canales que cubren los hechos en ese momento. El usuario puede ver todo en conjunto o seleccionar uno y saltar cuando quiera a otros para contrastar las ofertas. También son resaltables los servicios de usos internos como el registro de entrada u otros comportamientos del usuario relacionados con el canal al objeto de obtener datos estadísticos que puedan explotarse con otros fines de marketing.

\subsubsection{Según los sistemas técnicos de emisión}

Dentro de ellos hay que referirse a la interactividad introducida en la televisión digital terrestre o en la de satélite mediante otro canal de retorno como el de la telefonía, y en la de cable y ADSL con un retorno por el mismo sistema según la capacidad de ancho de banda, pero con asimetría entre la oferta y la respuesta.

\subsubsection{Según sistemas técnicos de recepción}

Uno de los problemas de la TDT es la falta de homogeneización de los equipos descodificadores de tal manera que está impidiendo a los usuarios el acceso a los servicios interactivos. Lo frecuente es la instalación de los descodificadores más simples como los zappers, prácticamente sin capacidad interactiva más allá de la selección de canales y algunas informaciones añadidas. Los equipos de recepción Set Top Box sirven para algunas funciones de acceso, pero no para el desarrollo de una plena interactividad. EI PVR (Personal Video Recorder) es un grabador-reproductor de alta capacidad de gigas y de horas con posibilidad de pausas, adelantos, retrocesos, pero también con escasa interactividad. El descodificador con mayores prestaciones y que se va aceptando en Europa y en particular en España es el MHP (Multimedia Home Platform), el cual aporta una elevada capacidad de almacenamiento y de acceso a multitud de servicios y permite una plena interactividad (Foro Técnico, 2005). Sin embargo, en España la inmensa mayoría de los equipos instalados son los zappers y muy pocos los de MHP, lo cual provoca que no se incorporen muchos servicios interactivos o que, los que se experimentan, no pasen de su fase inicial por no existir usuarios suficientes. Una de las mayores aportaciones de la digitalización ha sido la incorporación del mando a distancia al dar un gran poder de zapeo o de recorrido por los canales a los usuarios. No es una mera aportación tecnológica, sino un cambio en el proceso comunicativo ya que cada usuario potencia su capacidad de selección dentro de las ofertas y, además, puede asumir el salto a la interactividad comunicativa. Cada usuario crea su propia secuencia en el visionado de canales y, por tanto, efectúa el seguimiento de relatos en varios canales. Los televisores con mayor capacidad interactiva promueven que cada usuario efectúe una autoprogramación según sus propios gustos. El MHP aporta también la opción de la división de pantalla por parte del emisor, así como diversas opciones de formato de pantalla por parte del usuario al permitir una capacidad multiplicadora de ventanas dentro de la pantalla. Esto supone unas grandes transformaciones en los formatos de programas y en la narrativa final. Además de la narrativa propuesta por el canal 
los usuarios pueden generar también otra propia. Para ello se requiere estar imbuido de una cultura visual digital como ha señalado Andrew Darley (2002) y manejar con cierta pericia los códigos y géneros audiovisuales.

\subsubsection{Según proceso comunicativo de recepción por los usuarios}

El usuario pasa del zapeo que le otorga el mando a distancia a un comportamiento interactivo en el que establece un pleno proceso comunicativo en doble dirección con la información y con otros usuarios. Se convierte en un interactivista comunicativo. Tal realidad se efectúa mediante una apertura al diálogo $\mathrm{y}$, en algunos casos, según las opciones que le ofrezca el diseño del modelo, para una creatividad personal. La interactividad se incrementa por la capacidad y el desarrollo de búsquedas y recorridos personales que desee efectuar. En suma, en este caso la modalidad interactiva televisiva permite pasar de la concepción comercial de la audiencia a una promoción o freno de su capacidad participativa real.

\subsubsection{Según el análisis vertical de las ofertas concretas}

Dentro de las ofertas de la TDT sobresalen, a fecha de febrero de 2006, los siguientes:

1. RTVE: Lanzadera, EPG, teletexto digital, servicios vinculados a programas, tiempo, tráfico, bolsa, vídeo reescalado, emplea-T, banner publicitarios.

2. Antena 3, Neox y Nova: Lanzadera, EPG, teletexto digital, ticker $^{10}$, juegos, encuestas.

3. Cuatro, $\mathrm{CNN}+, 40$ Latino: EPG, infobolsa, música y radios, Méteo, Onceplus.

4. TV3: Lanzadera, EPG, suite MHP o catálogo de aplicaciones, 3i: canal TDT con las aplicaciones que ofrece su múltiplex, teletexto, iTicker, iMeteo, iChat $^{11}$, iVote ${ }^{12}$.

5. Telemadrid: Lanzadera, chat, televisión enriquecida, teletexto, tráfico, juegos.

\subsubsection{Según el creador}

No toda la interactividad que se exhibe en un canal es propia, sino que puede estar producida por otra entidad ajena. En este caso el canal se dedica

\footnotetext{
${ }^{10}$ Servicio que permite difundir información en forma de titulares escritos sobre la pantalla. Cuando el usuario elige uno de ello, aparece la información ampliada.

${ }^{11}$ Permite publicar a modo de sobreimpresión en la pantalla los mensajes que van enviando los seguidores de su chat mientras se emite el programa. También permite la gestión y publicación de mensajes SMS de telefonía móvil.

${ }^{12}$ Servicio de participación de los usuarios en las respuestas a cuestionarios o sondeos que se hacen desde un programa.
} 
exclusivamente a la difusión de lo que le sirve otra empresa. Por tanto, existe una interactividad generada por el canal, los usuarios o ambos, otra interactividad creada por otras entidades que la televisión redifunde como los telejuegos y demás productos de simulaciones de realidades, y otra interactividad en canales de servicios organizados y diseñados por acuerdo entre el canal y la empresa promotora como los de telebanca, teletienda y otros.

\subsubsection{Según las relaciones entre emisores y receptores}

Aparece una interactividad de oferta potencial en un canal dentro de la cual se recogen muchos de los servicios señalados anteriormente. $Y$ emerge otra interactividad referida a los usuarios que, a su vez, cobra diversos aspectos; puede estar relacionada con la capacidad que brinda el televisor, o interactividad tecnológica, como sucede cuando el usuario divide la pantalla de un televisor digital en varias ventanas para seguir diversos canales o servicios; puede ser con la información o contenidos, es decir, con un diálogo en el que los usuarios reciben unos datos, añaden otros y al final se muestran los resultados en la pantalla. Además, los usuarios en algunos casos pueden incorporar sus producciones escritas o audiovisuales con respuestas, propuestas $u$ otras sugerencias. Todo ello permite que desde fuera del proceso pueda efectuarse una investigación sobre los usos y consumos reales de los interactivistas. Cabe también la vinculación entre unos y otros hasta organizarse una interactividad plena de emisores y receptores. $O$ también una interactividad exclusivamente entre los usuarios como en los videoblogs donde los canales sólo ponen el soporte para que se cree una red social de comunicaciones entre usuarios; el canal manifiesta una auténtica actitud de servicio ya que no interfiere en los contenidos.

\subsubsection{Según las exigencias multimedia de los servicios}

Es una modalidad centrada en la capacidad del sistema para integrar todos los recursos expresivos en los procesos de interactividad. Ya no es sólo una interactividad escrita, sino también oral y audiovisual. En este caso se propician también otros elementos propios de la concepción multimedia como la navegación y la complejidad de los enlaces hipertextuales e hipermedia entre iconos, vídeos, audio.

\subsubsection{Según vinculación con los teléfonos móviles.}

Es una modalidad creciente. Se emplea tanto para enviar como para recibir SMS, MMS, informaciones urgentes o de "alarma" e incluso se amplia a las transacciones de telebanca.

\subsection{Niveles de interactividad}

Los niveles de interactividad permiten conocer la mayor o menor riqueza de ésta, el planteamiento de los autores, su capacidad para admitir el diálogo real e incluso la plena capacidad de los usuarios para generar sus producciones y exhibirlas por el canal en red con otros participantes e interactivistas. Los resultados del análisis han aportado múltiples variables y que sintéticamente se 
sistematizan en varios campos que van desde los niveles conductistas hasta los constructivistas pasando por otros intermedios.

Los niveles conductistas se refieren a las orientaciones o imposiciones del canal para guiar a los usuarios a un destino determinado por él o al deseado por el usuario para obtener una información, efectuar una operación con la mayor rapidez posible o contactar con lo que pretenda. Sobresalen los siguientes:

Nivel 0: Difusión sin interactividad alguna. Aunque la emisora pueda realizar sobreimpresiones en las pantallas de datos, de resultados deportivos o de noticias, no hay posibilidad de interactuación alguna por el usuario.

Nivel 1: Zapeo por los canales y pausas, adelanto, retroceso con los reproductores. Puede incluirse también el del registro automático de entradas o usos selectivos de canales de programas por la audiencia. Es una interactividad eficaz para el consumo condicionado por las necesidades de selección, pero bastante pobre desde el punto vista de búsqueda de diálogo o intercambios.

Nivel 2: Selección entre opciones mediante categorías temáticas y numéricas sucesivas hasta llegar al punto deseado. Van desde las más simples como la selección por idiomas hasta las de opciones sucesivas como la del modelo del teletexto que parte de unas presentaciones numéricas: primer nivel según índice y segundo nivel según números por centenas y dentro de éstas por decenas. Hay otras opciones de tipo secuencial, es decir, varias opciones seguidas hasta llegar a la información deseada.

Entre los niveles conductistas y los constructivistas aparecen otros intermedios. No debe considerarse que cada nivel tenga unas fronteras tajantes. Son variables que permiten discriminar y evaluar la aportación de los servicios desde la perspectiva de la interactividad. Dentro de ellos cabe resaltar:

Nivel 3: Consumo a la carta o bajo demanda según catálogo como el modelo del Video on Demand (VOD) o el de pago por visionado (PPV). La TDT ha iniciado la oferta por Internet. Se presenta en una fragmentación de informaciones como en la cibertelevisión a la que puede accederse por un canal de retorno.

Nivel 4: Capacidad para que el usuario incorpore información: declaración de la renta, respuestas a encuestas, intervención de los telespectadores en los programas de concursos, televotaciones, apuestas deportivas, valoración de contenidos. También se incluyen aquí los servicios, aportados generalmente por canales dedicados exclusivamente a esta función, asociados a otras redes como los de telebúsqueda de datos o los de las transacciones de telecompraventa.

Nivel 5: Posibilidad de participar mediante el diálogo o intercambio del usuario con la emisora o entre usuarios según diversas opciones de Internet: videollamadas, videochats, videoforos.

Hay otras orientaciones constructivistas que fomentan la capacidad informativa y creativa de los usuarios para generar sus contenidos, intercambiar informacio- 
nes o producciones con otros o llegar hasta instalarse en la realidad virtual. Entre ellos descuellan los siguientes:

Nivel 6: Capacidad para generar simulaciones multimedia: videojuegos, video interactivo, juegos de rol.

Nivel 7: Interactividad con la publicidad en la que se requiere, por ejemplo, ejecutar correctamente un juego, acertar unas pruebas o asociar productos y sus características con respuestas adecuadas. Se mantiene un diálogo hasta la consecución o pérdida de un premio.

Nivel 8: Creación plena a través de herramientas aportadas por el canal para generar espacios o diferentes escenarios, personajes con diversa tipología y tratamientos audiovisuales con el fin de propiciar producciones realizadas por el usuario.

A estos niveles presentes en la TDT se añaden otros de gran innovación como los compartidos con otras modalidades o extensiones de la televisión en general y más en particular con los de las plataformas de las redes sociales.

Nivel 9: Exhibiciones y descargas de producciones de cualquier usuario dentro de las plataformas de las redes sociales como YouTube, MySpace o de intercambios con otros usuarios mediante las redes $P 2 P$.

Nivel 10: Creación plenamente virtual como en Second Life para producir un universo virtual interactivo.

La interactividad está vinculada a los otros dos amplios campos de todo multimedia: la navegación y los enlaces. En cada uno de los dos casos también aparecen unos modelos diferentes caracterizados por la mayor o menor claridad, capacidad y control. Todo ello llevaría a una interoperatividad de los servicios interactivos (Unión Europea, 2006).

Aparecen unos modelos de búsquedas internas dentro de la Guía Electrónica de Programación según la ramificación por categorías, subcategorías y secuenciación numérica, la vuelta a otras categorías según colores del mando o el recorrido por canales según clasificaciones establecidas en la EPG, bien de programas y de otras informaciones o bien dentro de otras ofertas del grupo de comunicación.

Hay otros modelos de búsquedas externas con el riesgo que esto supone, ya que una vez que el usuario se va de la dirección propia a otras es muy probable que no vuelva. Esta es la razón por la que este modelo tiene escasa presencia en la TDT. Y cuando aparece hay que examinar con qué otras informaciones se establece la navegación. Lo más común es que sólo se efectúe con otras páginas webs mediante grandes buscadores como Google o mediante buscadores específicos de televisión, todavía muy escasos.

Los enlaces presentan también cierta complejidad. Existe un modelo centrado exclusivamente en la vinculación con la información interna mediante el hipertexto (asociación entre textos escritos) e hipermedia (asociación entre cualquiera de 


\section{Modalidades y niveles de interactividad en la Televisión Digital Terrestre}

los sistemas expresivos) en la web: iconos, vídeos, audio, o dentro de los canales de la miniplataforma o gran plataforma dentro de uno o varios múltiplex. Y existen otros enlaces externos con plataformas ajenas dentro del mismo sistema de difusión como en el satélite, desde la web con otras webs del grupo de comunicación alejados de la televisión, otros medios u otras empresas, y enlaces relacionados como www.hispalista, www.youtube.com.

\subsection{Transformación del proceso comunicativo por la interactividad}

Las modalidades de interactividad en la TDT están repercutiendo también en los propios modelos de comunicación interactiva. La TDT aporta elementos específicos a los modelos generales de la comunicación e información interactivas y modifica los principales componentes del proceso de comunicación televisiva en los siguientes aspectos:

1. Interactividad del emisor en su oferta. Propuesta de diálogo dentro de unos límites controlados totalmente por el emisor de los mensajes.

2. Canales interactivos o infraestructura tecnológica interactiva: antenas, módem y televisores con zapper, PVR, MHP y sus correspondientes diferencias interactivas, que actúan por el mismo sistema como en la televisión por cable o por otro como lo realiza la TDT por las redes telefónicas.

3. Contenidos y servicios interactivos según niveles de complejidad y creatividad. Nacen los contenidos en red, es decir, con opciones de asociaciones y vinculaciones de cualquier tipo de manera automática según las intenciones de los usuarios.

4. Tratamientos interactivos de manera aislada o integrada de la escritura, iconos, imágenes fijas y en movimiento y sonidos. Es el desarrollo de la hipertextualidad y de la hipermedialidad desde el ámbito de la televisión.

5. Tiempos interactivos: sincrónicos, asincrónicos y asimetrías de uso entre oferta y usos. Los usuarios pueden elegir cualquiera de estas opciones y acomodar los tiempos a sus necesidades.

6. Interactividad en el espacio in situ o a distancia: nacional, autonómica, local. Surge una encrucijada glocal de usuarios en la que la información puede llegarles de diversas procedencias espaciales externas e internas en el lugar en que activa el proceso.

7. Cibermundo en el que se integra la televisión real y la televisión virtual como sucede en Second Life. Todavía se carece de datos fidedignos sobre la integración de ambas y menos aún de su consolidación, aunque los primeros avances no auguran una fuerte implantación. No obstante, desde el punto de vista de la comunicación interactiva es una experimentación de grandes aportaciones.

8. Interactividad de usuario-receptor con máquinas e información. Se centra en las opciones de los usuarios en su búsqueda de información o en la publicación de sus producciones o investigación de procesos de usos interactivos. 
9. De pleno intercambio de papeles entre usuarios emisores y usuarios receptores que da origen al auténtico EMEREC (Cloutier, 2001), es decir, al usuario que ejerce alternativa o indistintamente de emisor o de receptor.

10.Usos reales de interactividad por los usuarios según la técnica investigadora de la observación de los procesos interactivos o de recepción-producción.

\section{CONCLUSIONES}

De todo lo indagado se deducen unas conclusiones sobre la implicación y desarrollo de las modalidades y niveles de interactividad en la TDT.

Asistimos todavía a la fase transitoria del paso de lo analógico a lo digital y esto se observa en todos los procesos de la TDT. No acaba de implantarse con sus ofertas de programación ni con sus servicios y, en consecuencia, las modalidades y niveles de interactividad se encuentran todavía en situación de meros tanteos.

Se requiere un cambio de mentalidad de una televisión de difusión a otra interactiva. Sigue pesando la mentalidad de la televisión tradicional y no acaba de creerse demasiado en la digital. De hecho, las modalidades y niveles de interactividad se han obtenido de unas ofertas que apenas sobrepasan la experimentación. No acaban de consolidarse unas aplicaciones que permitan obtener claramente unos resultados sólidos.

Hay una necesidad de incorporar la interactividad en el diseño inicial de la programación y en el de cada uno de los programas y servicios de manera global. Sin embargo, persiste la concepción, realización y ofertas por separado.

Es preciso fomentar una experimentación para la concreatividad y, en suma, impulsar una nueva cultura de la interactividad entre los productores y los usuarios que se una a las culturas tradicionales: la oral-sonora propia de la radio, la escrita-gráfica específica de la prensa y la audiovisual compartida por el cine y la televisión, entre otros medios.

La cultura interactiva vinculada a la navegación y a los enlaces es la punta de un nuevo modelo expresivo multimedia que va más allá del audiovisual propio de la televisión tradicional y que caracteriza la nueva etapa digital de la televisión. Es la gran innovación respecto de las ofertas tradicionales.

Gran parte de las modalidades y niveles de interactividad examinados datan de hace años y no se aprecian grandes cambios en la actualidad. Es de esperar que con el apagón analógico del 3 de abril de 2010, según lo establecido por el Gobierno, se apueste definitivamente por las opciones que aporta la televisión digital terrestre para impulsar nuevos servicios y otros modelos de interactividad. 
22 Modalidades y niveles de interactividad en la Televisión Digital Terrestre

\section{REFERENCIAS BIBLIOGRÁFICAS}

AA.VV. (2007): Alternativas a la televisión actual. Barcelona: Gedisa.

BROWN, A.; y PICARD, R. (eds.) (2005): Digital Terrestrial Television in Europe. Londres: Lawrence Earlbaum.

BUSTAMANTE RAMÍREZ, E. (2008): La televisión digital terrestre en España. Por un sistema televisivo de futuro acorde con una democracia de calidad. Madrid: Fundación Alternativas.

CEBRIÁN HERREROS, M. (2004): Modelos de televisión: generalista, temática y convergente con Internet. Barcelona: Paidós.

CLOUTIER, J. (2001): Petit traité de communication. Emerec à I'heure des technologies numériques. Montreal: Carte Blanche.

DARLEY, A. (2002): Cultura visual digital: espectáculo y nuevos géneros en los medios de comunicación. Barcelona: Paidós.

FORO TÉCNICO DE LA TV DIGITAL (2005): Informe sobre servicios interactivos básicos basados en MHP. Madrid.

GAPTEL (Grupo de Análisis y Prospectiva del Sector de las Telecomunicaciones) (2005): Televisión digital. Madrid: Red.es.

MARZAL FELICI, J.; y CASERO RIPOLLÉS, A. (eds.) (2007): El desarrollo de la televisión digital en España. La Coruña: Netbiblo.

PEÑAFIEL SÁlZ, C. (ed.) (2007): Transformaciones de la radio y televisión en Europa. Bilbao: Servicio de Publicaciones de la Universidad del País Vasco.

RODRÍGUEZ PARDO, J. La televisión digital terrestre en el derecho comparado europeo. En AZURMENDI, A. (dir.) (2007): La reforma de la televisión pública española. Valencia: Tirant lo Blanch.

TELEDIGITAL: Especial 2007. Madrid.

UNIÓN EUROPEA (2006): Comunicación sobre interoperatividad de los servicios de televisión digital interactiva. COM (2006) 37 final.

\section{Breve semblanza biográfica del autor}

Mariano Cebrián es Catedrático de Periodismo de la Universidad Complutense de Madrid. Es autor de más de treinta libros de autoría individual y más de ochenta de autoría colectiva, así como de más de un centenar de artículos en revistas científicas. Es asesor científico de diversas colecciones de libros sobre comunicación. Es miembro de Comités científicos de casi una veintena de revistas españolas y extranjeras. Participa como conferenciante invitado en Congresos nacionales e internacionales. Es investigador principal de varias investigaciones financiadas por el Ministerio de Educación y Ciencia y otras entidades. Es presidente de la Asociación Española de Cine Científico. 